\title{
Meanings Over Time of Working as a Nurse in Elderly Care
}

\author{
Karin Blomberg*, Inger James and Annica Kihlgren \\ School of Health and Medical Sciences, Örebro University, Örebro, Sweden
}

\begin{abstract}
Background: Although registered nurses (RNs) play a central role in the care of older persons, their work in elderly care has historically been described as "low status" in nursing. This is especially problematic due to the global issue of RN turnover, but there is still little evidence of how to change this trend. Better understanding is needed of the reasons why RNs work in elderly care, as well as knowledge of whether these reasons have changed over time.
\end{abstract}

Aim: The aim was to explore the meaning of working in elderly care, over time, from the perspective of RNs.

Method: We interviewed thirteen RNs working in nursing homes, six of them in 2000 and the remaining seven in 2012, and analysed the resulting data using Interpretive Description.

Results: The results show similarities and differences over time in the RNs' reasoning about the meaning of their work with older persons, from a focus on obstacles to a view of opportunities.

Conclusion: An RN's intention to continue working in elderly care might be based on their beliefs; their view of older people, and their experiences of being able to influence the care. Managing this knowledge could be an essential factor in reversing the historical trend of RN work in elderly care being seen as low status, and the increasing turnover in such nurses. Our results could stimulate reflection on daily care and beliefs about caring for older persons.

Keywords: Beliefs, elderly care, registered nurse, nursing.

\section{INTRODUCTION}

The number of older people in need of care is expected to increase as the population continues to age. Although politicians both nationally and internationally emphasise the goal of quality of care for older people, regardless of where it takes place, there is no definition of the level of education, experience, or other qualifications this requires. Registered nurses (RNs) play a central role in the care of older persons, but their work in elderly care has historically been described as "low status" in nursing [1]. Today, this historical trend is obvious in the lack of RNs interested in working in elderly care, at a time when the need for competent nurses is likely to increase.

Nurse turnover is a global problem [2], and there is still little evidence of how to change this multifaceted state. Excessive turnover among nurses working in elderly care carries a risk that both the quality and safety of care may be negatively affected. Today it is well documented that the quality of care is related to work satisfaction among nurses in different contexts [3, 4], especially in care of older persons, as it has been inversely related to high levels of staff turnover [5-8]. Several studies have described the working conditions among nurses in elderly care. Josefsson et al. [9] found high levels of time pressure, greater demands on knowledge, and greater emotional and conflicting demands in dementia care, in comparison to RNs working in general wards. Weman, Kihlgren, and Fagerberg [10] showed that

*Address correspondence to this author at the School of Health and Medical Sciences, Örebro University, S-70182, Örebro, Sweden; Tel: +46-19-30 12 70; Fax: +46-19-30 36 01; E-mail: karin.blomberg@oru.se almost half of RNs working in elderly care were not satisfied with their working situation.

Working as a nurse in elderly care has also been described in a positive manner. The RNs who find their working situation most stimulating are those with fewer than 5 years of work experience. The experience of working as a RN in elderly care has been described as involving a workplace of convenience, with enjoyment being promoted by contact with residents [11]. Moreover, teamwork, social support, and role clarity have been shown to have a positive association with job satisfaction and a negative association with burnout and stress [12]. Education and supervision are other documented explanations for health care professionals' satisfaction in elderly care [13, 14].

There is, however, a lack of studies exploring nurse turnover in care of older persons, and most of the existing research was performed in acute settings and with a crosssectional design [2]. The literature describes a myriad of relationships and mediating effects among variables related to turnover, such as generational diversity among the staff; the organizational climate; experience of workload, stress, and burnout; management style; perceptions of empowerment by nurses; different role perceptions; and individual factors including level of education and amount of nursing experience $[2,15]$. There is a need for longitudinal studies including both quantitative and qualitative approaches, to explore the values that influence both the nurses' intention to stay in their position and their decision to leave $[2,16]$. The need for in-depth research giving RNs the opportunity to explain in their own words has already been raised [15]. The increasing turnover of RNs is problematic 
especially with the lack of nursing students and RNs interested in working in elderly care today, at a time when the need for competent nurses is likely to increase. In order to develop interventions to address the above problems in elderly care, there is a need for increased knowledge and a better understanding of the reasons why RNs work in elderly care, as well as whether these reasons have changed over time i.e. between 2000 and 2012. The aim of this follow-up study was therefore to explore the meaning of working in elderly care, over time, from the perspective of the nurse.

\section{MATERIALS AND METHODOLOGY}

\section{Design}

This follow-up study had an explorative design with a qualitative approach. We interviewed RNs on two occasions, in 2000 and in 2012 in order to explored similarities and differences in the nurses' reasons over this time.

\section{Sample}

The RNs were strategically selected from different nursing homes within a municipality in Sweden, from among those staff with more than five years' experience of working with older people. One difference in the context of the RNs between the years was that in 2000 the nursing home was newly opened. The participants consisted of six RNs (aged 30-45, all women) in 2000 and seven RNs (aged 32-58, 6 women and 1 man) in 2012.

\section{Data Collection}

The third author performed the interviews in 2000, and the second author performed the interviews in 2012; both are experienced researchers in elderly care. In accordance with the wishes of the interviewees, we conducted the interviews at their place of work. We chose to use open interviews in order to gain a deeper understanding of the RNs' views on working in elderly care [17]. On both occasions, we asked the same question i.e. their experiences of caring for older persons at the start of the interview. We encouraged the RNs to speak as freely as possible about their expectations of their work and their experiences, and used follow-up questions such as "Please tell me more about that" or "What do you think about that?" The interviews were audio recorded with the participants' permission, and each lasted 60-90 minutes. An experienced secretary transcribed all interviews verbatim.

\section{Data Analysis}

We read the transcripts repeatedly to obtain a sense of the data as a whole. The analysis was based on interpretive description [18], an inductive approach built on the key axioms of naturalistic inquiry [19]. We initially grouped the RNs' descriptions of working in community care by their meanings of working in elderly care, resulting in a preliminary categorization scheme. In the next step, we divided the interviews into two groups, one with the interviews from 2000 and one with those from 2012, and then analysed these groups in relation to each other i.e. similarities and differences between these data. We asked the question "How do the RNs describe their work in 2000 and in 2012?" in order to find similarities and differences in the text. An overall dimension and five themes were identified across the data with subthemes describing similarities and differences over time. All authors discussed and validated the preliminary findings. Quotations are presented below to illustrate the findings, having been translated from Swedish to English by an authorized translator. Hesitations and unnecessary words are indicated by (...), and square brackets [ ] indicate comments from the authors.

\section{Ethical Consideration}

Permission to interview RNs in community care in 2000 was given by the Regional Ethics Committee (803/99). Approval for the further interviews 12 years later was granted by the Regional Research Ethical Committee (2011/009). The RNs were not regarded as dependent on the interviewer in any way, and could decline participation in the study at any time without giving a reason.

\section{RESULTS}

The overall dimension "From a focus on obstacles to a view of opportunities in working in elderly care" included descriptions of how these nurses saw their work with older persons, a field that they had all actively chosen to work within. The meaning of working in elderly care ranged from a focus on obstacles to a view of opportunities. Below we describe this overall dimension in relation to the component five themes. The findings from the earlier interviews in 2000 are given first in each theme, followed by findings from the later interviews in 2012. Finally, we present a comprehensive synthesis of the results.

\section{Theme 1: The value of older persons' needs}

\section{A focus on obstacles - "Older persons are demanding”}

The nurses experienced the needs of the older persons as being demanding. Even when they expressed an understanding of this as being related to age and disease, they still experienced consequences such as less job satisfaction. They explained that helping the older persons could be rewarding, but that they also received complaints when the older persons did not feel they were being helped quickly enough.

"Sure, they are sometimes grateful, and then
you get some reward for your efforts. That
happens. But often it's complaints, that you
don't come fast enough." (RN5 2000).

The nurses described the needs of the older persons as being selfish, and the older persons themselves as being demanding, egotistical, and insistent on getting attention.

\section{"I have never met so many demanding old people ever. Because everyone here is basically clear in the head, and they can and do make demands." (RN1 2000).}

The RNs noted that the older persons did not seem to understand that there were other persons who were also in need of help. They also explained that the older persons' egotism required understanding from the carers.

\footnotetext{
"Unfortunately, I think that many people become egotistical when they get old. But it probably has to do with illness, so you try to think they haven't been this way their whole lives." (RN4 2000).
} 
A view of opportunities - "It is the older persons who decide."

The nurses listened to and followed the older persons' needs. If the interaction between a nurse and an older person failed to work out, for example if nothing the nurse said or did was good enough, the nurse could ask a colleague to take over. However, these situations sapped the nurses' energy. The nurses noted that the caring was performed individually and was tailored to the older person's needs and wishes. This meant that the nurse must be flexible and comply with and listen to the older person; this was also a way to show respect. It was the older persons who made the decisions; it was their home and their life, and the nurses and staff should respect that.

\section{"Here they become a person, I think, when we go to their house. I see how it is there, how they live and so on. So I'm a guest in their home." (RN6 2012).}

The nurses considered it important that the older persons should live their lives as they wished in their own homes.

"They can have schnapps. It's their house they decide. Get to smoke and eat snacks." (RN2 2012).

In order to meet the older persons' needs and wishes, it was important to get to know them and find out about their earlier lives. If the older person could not speak about their life history, perhaps their relatives could.

Theme 2: The value of caring time

\section{A focus on obstacles - "I'm not enough"}

The nurses described how a lack of time meant they essentially could not provide the care they wanted to give to the older persons. It was clear from the interviews that the nurses saw major deficiencies in their care, leading to a feeling of inadequacy and the feeling that there was not enough time to give good care. The low numbers of personnel led to poor-quality care, and there was a discrepancy between the residents' need for nearness and the caregivers' available time. Often, the older person's needs could not be met due to the lack of time. The nurses felt they could not take personal integrity into consideration, and the care was not adapted to the individual. Situations involving different kinds of violation of the older persons were described, such as power relationships, insults directed at the older persons, and "rude" ways of relating.

\section{"... if you think that they need to go to the bathroom, so to speak...it should be a right...but often they just have to pee in a diaper...you don't have time and they can't go themselves..." (RN2 2000).}

However, the nurses gave priority to the older persons' needs, and put their own selves to one side in favour of keeping up with providing care. They also expressed the desire to be able to get time and peace to focus on care:

$$
\begin{aligned}
& \text { “...to be able to take it easy with them, not feel } \\
& \text { stressed because you have to do this and that } \\
& \text { later in the day. To be able to give things the }
\end{aligned}
$$

time they need, that's when it feels good for me." (RN6 2000).

There were also days where there was time to do things other than those that absolutely needed to be done, and these were the days that the nurses longed for. A good day for a RN could be when there were enough personnel and the weather was nice, so the older persons could go outside or the nurse could sit on the edge of the bed and talk.

\section{A view of opportunities - "I have to be flexible"}

The nurses expressed that they had time to care, even if it was not optimal. They made an active choice not to become stressed, and to provide the best possible care, adapted to the older persons' needs and wishes.

It was clear from the interviews that the RNs had chosen to work within elderly care because they felt that in this context there was enough time to give care to the older persons. Several of them had previously worked at the county hospital, where the work had been more stressful and they did not have enough time for the patients. At their current workplace, within elderly care in the community, the work was less stressful:

\section{"No, I did think it was a bit of an assembly line there at the hospital. I... - want to take some time with the residents. I think that's quite nice." (RN7 2012).}

However, the nurses' administrative work took time away from the possibility to be near the older persons and participate in the direct care. Some of the nurses noted that the perceived lack of time could become a mental barrier, and this in turn could mean that the efficiency of the care suffered.

\section{"It can be a mental obstacle too. That sometimes makes you less efficient in what you do too." (RN7 2012).}

In this case it could be better to accept that work in community care entails a lot of administration. Changes in the older persons' health meant that the care had to be flexible and ongoing planned, which in turn meant more administration. Some of the nurses made an active choice not to become stressed about their work, even if they lacked time to ensure the best possible care. Despite this, they wished that they had more time so that they could perform nursing care in a different way.

$$
\begin{aligned}
& \text { "Sometimes I feel like I wish we had more } \\
& \text { nurses. That we shouldn't be basing things on } \\
& \text { this much delegation." (RN6 2012). }
\end{aligned}
$$

Theme 3: The value of caregivers' work

A focus on obstacles - "The organization does not work (but I like the older person)"

The nurses perceived that the organization did not work, nor did their collaboration with colleagues; both were essentially obstacles. However, they found reciprocity in their relationships with the older persons.

Several of the RNs had previously worked at the county hospital, and had not been prepared for the fact that their new workplace was organized in a completely different way. 
Working in a new place brought both difficulties and the chance to get inspiration to be creative.

"In established workplaces, everything is already settled, but in a new place, you can get new inspiration." (RN1 2000).

The nurses had also experienced that there were different cultures in different organisations, making it hard to switch organisations. Starting to work in a new organisation is demanding, and if the organisation does not work, the nurse may decide to leave. Our informants expressed both admiration for those who had sustained long careers within elder care, and concerns about having the energy to get to retirement.

"You wonder how long you will have the energy for health care; I have at least 20 more years to work." (RN6 2000).

There were also statements about negative influences from colleagues who did not get on with their work, and thoughts about looking for new jobs. There's nothing they just said because the chance of getting a job was easy.

"But it is difficult when people talk about applying elsewhere...because jobs seem to be available everywhere." (RN3 2000).

However, the RNs said that they enjoyed working with older people, and felt that the work suited them. They appreciated their relationships with the older persons, and considered having conversations with them to be fun and rewarding. There was reciprocity in these relationships; the nurses got something back from the older persons.

A view of opportunities - "I have an opportunity to make it better"

The nurses experienced their work as an opportunity to gain a holistic perspective and to influence the older persons' health. The work was characterized by collaboration, and relationships were created with the older persons, their relatives, and the nurse assistants.

The nurses who had worked at the county hospital noted that the patients there generally stayed for only a short length of time, and that they had had little opportunity to monitor these patients' care. They had made an active choice to work within community elderly care, to get a holistic view of the older person's situation. This allowed them to follow and influence the older persons' lives to be as good as possible, thus enriching their work:

"But I guess the thing is that I feel I can help someone to have a good life during their last period in life. I can't cure them, but I can see to it that their lives are as good as possible. And you're there through the whole process." (RN5 2012).

The nurses had a responsibility to all older persons, and hence sought a holistic view of the older persons' health status, which they then conveyed to the other staff. However, the nurses were not able to meet all the older persons they were responsible for; the staff members closest to the older persons were the nurse assistants. The nurse assistants became the nurses' eyes and ears, following the older

persons' state of health and reporting this to the nurses. The nurses also collaborated with the older persons' relatives, allowing them to gain knowledge of the older persons and obtain a holistic view of their lives.

The nurses enjoyed their work with the older persons because it was based on reciprocity and collaboration, and allowed them to establish relationships with the older persons, their relatives, and the nurses' own colleagues.

"Yes, it's like you get this relationship, actually. Both with your colleagues and the staff, and with the patients and their relatives." (RN2 2012).

Theme 4: The value of teamwork

A focus on obstacles - "It is impossible to be a team"

The nurses considered the team to be important, but found it was difficult to work as a team when the organization was unstructured and communication was lacking.

"We haven't got a real structure yet at work...that is what has been difficult." (RN5 2000).

Those who would lead and distribute work i.e. managers had different ideas which influenced the work. The RNs said that there was a lack of clarity in the communication and cooperation between RNs, doctors, and head nurses.

"We talked with our doctor and she thought we should have an oxygen tube, but the head nurse disagreed...it was difficult, with that and with different opinions about things." (RN2 2000).

The nurses saw the organisation as unstructured compared with their earlier experiences. They expressed dissatisfaction with their managers' decisions to recommend local guidelines instead of the national guidelines provided by the government; the RNs were accustomed to following routines from the National Board of Health and Welfare.

A view of opportunities - "We can learn from each other"

The nurses noted the importance of the team and the collaboration with the nurse assistants; it was the nurse assistants who were closest to the older persons. The care was designed through the team of nurses, nursing staff, and occupational therapists, and it was also the team that could initiate changes. The nurses felt the lack of a manager in the team. They saw a danger that the managers were so far away from the actual caring work that they would not be able to understand it.

\begin{abstract}
"That's why we miss the manager more. Oh I do know that - that we've said that in these team meetings, that we're supposed to have that unfortunately not everyone has - the team manager should participate. And I think that's really important. Otherwise I think they get too distant from the care." (RN4 2012).
\end{abstract}

The teamwork between the nurses and nurse assistants meant that they helped each other with the work, and the nurse assistant acted as the nurse's extended arm. 
“As a nurse it's really hard since we're not there the whole time to see what's going on, so we have to be able to work with the nursing staff too. Have a team, sort of." (RN3 2012).

Within this collaboration, the RNs and nurse assistants could learn from each other. The nurses could show the nurse assistants how they should behave towards the older persons; and the nurse assistants, who were closest to the older persons and knew them best, could show the nurses how each individual older person preferred to have their care performed.

Theme 5: The value of management

A focus on obstacles - "Where is the boss?"

The nurses felt the lack of a knowledgeable, involved manager who dared to make decisions and was present at the workplace. The interviews included expressions that could clearly be related to the competence of the management and their presence at the workplace.

"Sure, they [the managers] are important. They should be engaged and all that. And I think it is important that if they say they are going to look into something, they do it, and this is where it has been lacking." (RN1 2000).

The RNs thought that the management had a significant function, but they also understood the exposed position and complexity in the management's role. However, they wanted to have a manager who knew how things worked, and who got involved and got things done. They believed that managers ought to have experience in elder care and should really stand for what they say. The nurses made several statements about whether the manager should be a RN or not, and questioned whether a manager who was not a RN could understand the meaning of the questions asked by a RN on duty. They described having had a number of managers who did not know anything about health care. Absent management was a concern, as were uncertainties about the schedule and work times.

"...there is a lot that should be taken care of that doesn't get done... a lot that is said that doesn't get checked, and it gets annoying then...it is an annoyance for everyone." (RN3 2000).

However, it was important, regardless of profession, that the manager was a person who took responsibility and handled the problems occurring in the workplace.

A view of opportunities - "I can be the boss"

The nurses said that they could take responsibility for managing the work when they had an overall perspective of the older person's situation and everyday life. However, they lacked the power the manager had to lead the work, which could be a concern when the manager was absent. They saw themselves as the only staff members who had a holistic perspective on the older person's situation. They planned, organized, and administrated the care around the older person. It was important to be an authority in the management to the staff at the same time as it was important to act as a coach. The nurses had a great responsibility within the staff group, which included many agency staff. They also noted that the work should be well planned and structured.

"There is a lot to do with regard to planning, getting the full picture, and making sure there's a good basis for the nursing staff... I mean, good work lists and coaching them [the staff] because you have so many patients so you can't do it all yourself." (RN2 2012).

The nurses missed having a manager in the team, because they found it difficult to organise the work without having access to the powers of a managerial position.

"Because I miss that. I'd like to include the
manager more because she often has the
answers, after all." (RN1 2012).

\section{SYNTHESIS}

A common thread in both the earlier and later interviews with the RNs was that they appeared to want to provide the best care possible for the older person's needs. However, there were also discrepancies between the two groups of interviews, see Table $\mathbf{1}$. In the earlier interviews, the RNs described the older persons as demanding, which gave them less work satisfaction. The RNs felt insufficient, and saw major deficiencies in the care they provided. There were descriptions of deficiencies in the organization, lack of supervision, and a lack of collaboration or teamwork. The RNs mainly saw obstacles, and expressed a lack of solutions and initiative to handle these problems. The later interviews, on the other hand, revealed that the nurses were flexible and adaptable to the older persons' needs. Their work provided an opportunity to get a holistic perspective and to influence the older persons' daily lives and health. There were also descriptions of collaboration and relationships with the older persons, their relatives, and the nurses' own colleagues. The

Table 1. Similarities and Differences in Meanings of Working as a RN in Elderly Care, Described by RNs in 2000 (n=6) and in $2012(n=7)$

\begin{tabular}{|c|c|}
\hline RNs Working in Elderly Care in $\mathbf{2 0 0 0}$ & RNs Working in Elderly Care in 2012 \\
\hline \hline Older persons are demanding & It is the older persons who decide \\
\hline I'm not enough & I have to be flexible \\
\hline The organization does not work (but I like the older person) & I have an opportunity to make it better \\
\hline It is impossible to be a team & We can learn from each other \\
\hline Where is the boss? & I can be the boss \\
\hline
\end{tabular}


RNs saw the older persons and the nurse assistants as the most important participants in their work. These RNs saw the opportunity and took the responsibility for leading the work in a team.

\section{DISCUSSION}

Our findings show similarities and differences over time in the RNs' reasoning about the meaning of their work with older persons. In the later interviews (in 2012), the RNs seemed to be more focused on the opportunities in their work and the possibilities to create relationships with the older persons and their relatives. They also described that they took a leadership role in the teamwork, and valued the older persons and the nurse assistants as the most important participants in the work. There was an overall focus on the older person's needs. From a societal perspective, a number of changes occurred within Swedish elderly care during the twelve years between the interviews. A set of national core values for the elderly were introduced in 2011, aimed at ensuring older persons a life of dignity and well-being, and including the ethical values and norms that should direct the care of such persons [20]. Although these directives almost exclusively take a "top-down" perspective, the question is whether the directives have had an impact on the RNs' views and beliefs about their work. Our beliefs can be seen as "the lenses through which we view the world" [21], and these beliefs influence the way we interpret and act in different situations [21]. The RNs' intention to continue working in elderly care might be based on their beliefs; that is, their view of older persons and their experiences of being able to influence elderly care. The way in which we manage this knowledge could be an essential factor in reversing the historical trend of RN work in elderly care being seen as low status, and the increasing nurse turnover. A shift in attitudes must occur, from a focus on problems to a more positive view of the meaning of working as a $\mathrm{RN}$ in elderly care. Thus, interventions in elderly care must be based on a "bottom up" perspective i.e. working together with "the participants" [22].

The interviews conducted in 2000 were interpreted as lack of a humanistic approach; disregarding behaviour was observable in the RNs descriptions of their work in elderly care, meaning that the older persons did not get the support they needed. Dahlberg [23] described suffering from care as suffering arising from the relation between patient and staff when the focus of care is shifted from the patient's suffering to the staff themselves and their needs. The RNs interviewed in 2012 seemed to be more person-oriented rather than taskoriented, which is in line with the recent movement to a more person-centred care [24]. However, the findings did not indicate the quality of care, and there might be a gap between our informants' descriptions of their work and how RNs really act. Nevertheless, the obvious striving of the RNs to create a caring relationship with the older persons and their relatives is likely to be of decisive importance for how the quality of the care will be experienced.

It seemed in the 2012 interviews that collaboration was central in the RNs' reasoning. Collaboration was described in terms of support for the RNs and the possibility of learning from each other, but was also seen as essential in providing the best possible care to the older person. It is well known that the extent to which different health care professionals collaborate may affect the quality and safety of care as well as patient outcomes [25-26]. The RNs also described the central role they played in creating a good relationship with the nurse assistants, which will probably have consequences for the nurse assistants' experiences of being empowered [27]. A lack of collaboration between professionals might lead to disrupted care that diverges from the fundamentals of holistic care; this was clear in the interviews conducted in 2000. However, responsibility lies not only with the individual $\mathrm{RN}$, but with the team, the organization, the care culture, the education system, and political decisions. Nursing education should be designed to include the possibility for discussing and reflecting on core values and one's own beliefs about caring for older persons and interacting with their relatives. This is necessary not only for creating better prerequisites for being able to care for older persons, but also for encouraging young people to become interested in working in elderly care. The future of elderly care lies in our ability to recruit and retain the next generation of nurses [28], and in the development of nursing competence [29]. Price [28] has emphasized the need for realistic and contemporary portrayals of the nursing profession and the role of RNs. Our findings, which focus on the meaning of working as a RN in elderly care today, could act as a "role model" in the formulation of career expectations and career decisions for the next generation of RNs [28].

\section{Methodological Considerations}

Conducting longitudinal qualitative research raised several methodological difficulties due to changes in the society, the elderly care i.e. more multi-diseased person are cared for today, as well as the changes in the study population during the time. It was impossible to conducting interviews with the same RNs due to a staff turnover over time. If we had conducted several interviews on repeated occasions with the same RN, we may have been able to provide a deeper and probably a more multifaceted picture of the meaning of working as a RN in elderly care. Another limitation might be that the earlier interviews were performed with RNs working in the same nursing home. It may be reasonable to assume that nurses at the same workplace shared the same care culture and thus had similar reasoning. On the other hand, the RNs in the later interviews expressed comparable reasoning even though they worked in different nursing homes. The number of participants could be seen as limited. To ensure the quality in the study, we strove to learn from the $\mathrm{RNs}$ and set our own preunderstanding to one side during the interviews and analysis of the data [30]. We conducted continuous critical discussions between ourselves, and tested alternative interpretations and counterarguments against the data. This study was based on a methodological approach built on the key axioms of naturalistic inquiry [19], to obtain clinically relevant and useful understanding [18] of RNs' reasoning about their work in elderly care.

\section{CONCLUSION}

Our findings described similarities and differences over time in RNs' reasoning about the meaning of their work with older persons, from a focus on obstacles to a view of 
opportunities in working. The RNs' intention to continue working in elderly care might be based on their beliefs; their view of older persons, and their experiences of being able to influence elderly care. Managing this knowledge could be an essential factor in reversing the historical trend of RN work in elderly care being seen as low status, and the increasing nurse turnover. This knowledge must be integrated in the organization, the care culture, and the education system. Our results could stimulate reflection over daily care and a discussion of what constitutes the meaning of working in elderly care as a RN, with a focus on core values and beliefs about caring for older persons and interacting with their relatives. If situations in elderly care are not handled in a way that is beneficial to the RNs, patients, and relatives, this may result in stress, non-optimal elderly care, and above all increased nurse turnover.

\section{AUTHOR CONTRIBUTIONS}

Study design: KB, IJ, AK. Data collection and analysis: KB, IJ, AK. Manuscript preparation: KB, IJ, AK.

\section{CONFLICT OF INTEREST}

The authors confirm that this article content has no conflict of interest.

\section{ACKNOWLEDGEMENTS}

We are grateful for the participation of the RNs in the study. This study was supported by grants from Örebro University.

\section{REFERENCES}

[1] Brown A, Draper P. Accommodative speech and terms of endearment: elements of a language mode often experienced by older adults. J Adv Nurs 2003; 41: 15-21.

[2] Hayes LJ, O'Brien-Pallas L, Duffield C, et al. Nurse turnover: A literature review - An update. Int J Nurs Stud 2012; 49: 887-905.

[3] McGillis Hall L, Doran D. Nurses' perceptions of hospital work environments. J Nurs Manag 2007; 15: 264-73.

[4] Kramer M, Schmalenberg C. Confirmation of a Healthy Work Environment. Crit Care Nurse 2008;28: 56-63.

[5] Ellenbecker C. A theoretical model of job retention for home health care nurses. J Adv Nurs e2004; 47: 303-10.

[6] Karsh B, Booske BC, Sainfort F. Job and organizational determinants of nursing home employee commitment, job satisfaction and intent to turnover. Ergonomics 2005; 48:1260-81.

[7] Sikorska-Simmons E. Predictors of organizational commitment among staff in assisted living. Gerontologist 2005; 45:196-205.

[8] van den Berg TIJ, Landeweerd JA, Tummers GER, van Merode GG. A comparative study of organisational characteristics, work characteristics and nurses' psychological work reactions in a hospital and nursing home setting. Int J Nurs Stud 2006; 43: 491505 .

[9] Josefsson K, Sonde L, Winblad B, Robins Wahlin T-B. Work situation of registered nurses in municipal elderly care in Sweden: A questionnaire survey. Int J Nurs Stud 2007; 44:71-82.
[10] Weman K, Kihlgren M, Fagerberg I. Older people living in nursing homes or other community care facilities: Registered Nurses' views of their working situation and co-operation with family members. J Clin Nurs 2004; 13: 617-26.

[11] Moyle W, Skinner J, Rowe G, Gork C. Views of job satisfaction and dissatisfaction in Australian long-term care. J Clin Nurs 2003; 12: $168-76$.

[12] Spear J, Wood L, Chawla S, Devis A, Nelson J. Job satisfaction and burnout in mental health services for older people. Australas Psychiatry 2004; 12:58-61.

[13] Häggström E, Skovdal K, Fläckman B, Larsson A, Kihlgren M Work satisfaction and dissatisfaction - caregivers' experiences after a two-year intervention in a newly opened nursing home. J Clin Nurs 2005; 14: 9-19.

[14] Fläckman B, Fagerberg I, Häggström E, Kihlgren A, Kihlgren M. Despite shattered expectations a willingness to care for elders remains with education and clinical supervision. Scand J Caring Sci 2007; 21: 379-89.

[15] Flinkman M, Leino-Kilpi H, Salanterä S. Nurses' intention to leave the profession: integrative review. J Adv Nurs 2010; 66: 1422-34

[16] Leiter MP, Price SL, Spence Laschinger HK. Generational differences in distress, attitudes and incivility among nurses. J Nurs Manag 2010; 18: 970-80.

[17] Kvale S, Brinkmann S. InterViews: learning the craft of qualitative research interviewing. $2^{\text {nd }}$ ed. Los Angeles: Sage Publications 2009.

[18] Thorne S. Interpretive Description. Walnut Creek, CA: Left Coast Press 2008.

[19] Lincoln YS, Guba EG. Naturalistic Inquiry. London: Sage Publication Inc. 1985.

[20] Swedish Ministry of Health and Social Affairs. Lagrådsremiss: Värdigt liv i äldreomsorgen. The council of legislation remittance: Dignity life in elderly care. 2010 [Retrieved: August 10, 2010]. Available from: http://www.regeringen.se/content/1/c6/14/05/55/ec 7854cb.pdf

[21] Wright LM, Bell JM. Beliefs and illness: a model for healing. Calgary: 4th Floor Press 2009.

[22] James I, Blomberg K, Liljekvist E, Kihlgren A. Working together for a meaningful daily life for older persons: A participatory and appreciative action and reflection project - the lesson we have learned. Manuscript.

[23] Dahlberg K. Vårdlidande - det onödiga lidandet. The unnecessary suffering from care. Nurs Sci Res Nord Ctries 2002; 22: 4-8.

[24] McCormack B, Karlsson B, Dewing J, Lerdal A. Exploring personcentredness: a qualitative meta-synthesis of four studies. Scand $\mathbf{J}$ Caring Sci 2010; 24: 620-34.

[25] Zwarenstein M, Goldman, J, Reeves S. Interprofessional collaboration: effects of practice-based interventions on professional practice and healthcare outcomes. Cochrane Database Syst Rev 2009; 8: 1-31.

[26] Martin, JS, Ummenhofer W, Manser T, Spirig R. Interprofessional collaboration among nurses and physicians: making a difference in patient outcome. Swiss Med Wkly 2010; 140: 1-12.

[27] Wadensten B, Engholm R, Fahlström G, Hägglund D. Nursing staff's description of a good encounter in nursing homes. Int $\mathbf{J}$ Older People Nurs 2009; 4: 203-10.

[28] Price SL. Becoming a nurse: a meta-study of early professional socialization and career choice in nursing. J Adv Nurs 2008; 65: 11-9.

[29] Finnbakk E, Skovdahl K, Störe Blix E, Fagerström L. Top-level managers' and politicians' worries about future care for older people with complex and acute illness - a Nordic study. Int J Older People Nurs 2012; 7: 163-72.

[30] Dahlberg K, Dahlberg H, Nyström M. Reflective lifeworld research. Lund, Sweden: Studentlitteratur 2008. 